\title{
A LEI DE MIGRAÇÃO COMO RESPOSTA AOS FLUXOS MIGRATÓRIOS NO BRASIL
}

\section{THE MIGRATION LAW AS AN RESPONSE TO MIGRATORY FLOWS IN BRAZIL}

\begin{abstract}
VLADMIR OLIVEIRA DA SILVEIRA
Pós-doutor em Direito pela Universidade Federal de Santa Catarina (UFSC). Doutor, Mestre e Graduado em Direito pela Pontifícia Universidade Católica de São Paulo (PUC-SP). Graduado em Relações Internacionais pela mesma Universidade. Professor Titular da Universidade Federal de Mato Grosso do Sul (UFMS). É Professor da Pontifícia Universidade Católica de São Paulo (PUC/SP).
\end{abstract}

\section{ANTÔNIO HILÁRIO AGUILERA URQUIZA}

Doutorado em Antropologia (Salamanca). Professor da Pós-graduação em Direito e professor da Pós-graduação em Antropologia Social da UFMS. Líder do Grupo de Pesquisa (CNPq) “Antropologia, Direitos Humanos e Povos Tradicionais”. Bolsista PQ2

\section{ANA CAROLINA DOS SANTOS}

Mestranda em Direito na Universidade Federal de Mato Grosso do Sul (UFMS). Pósgraduada em Direito Civil pela Pontifícia Universidade Católica de Minas Gerais (PUCMG). Graduada em Direito pela Universidade Federal de Mato Grosso do Sul (UFMS).

\section{RESUMO}

Objetivo: O objetivo deste estudo é analisar a superação do Estatuto do Estrangeiro de 1980 e a entrada em vigor da Lei de Migração de 2017, como resposta ao aumento 
dos fluxos migratórios no Brasil, bem como os impactos que a mencionada Lei pode causar futuramente.

Metodologia: Metodologicamente, a análise dá-se por meio do estudo do diploma legal supracitado, relacionando sua eficácia diante dos novos desafios migratórios e sua resultante substituição por um código mais moderno e alinhado aos tempos. Por tratar-se de um estudo descritivo e exploratório, utiliza-se o método dedutivo, bem como a revisão bibliográfica e histórica dos temas em questão.

Resultados: Conclui-se que a Lei de Migração brasileira adveio para ultrapassar a diferenciação entre nacional e não nacional, valorizando a dignidade humana e a proteção à vida frente ao local de nascimento ou local de origem. A evolução entre a legislação antiga e o novo diploma legal é notável, considerando-se que o novo instrumento normativo confere direitos que o Estatuto do Estrangeiro de 1980 jamais concederia, afirmando a posição do Brasil no panorama das migrações como um Estado que está atento à realidade, mesmo sem ter o poder econômico que os Estados ditos de primeiro mundo possuem.

Contribuições: A principal contribuição deste estudo é demonstrar, por meio da comparação entre os diferentes diplomas legais e a realidade, a renovada eficácia do novo diploma legal, que trata mais adequadamente das questões migratórias por intermédio de um embasamento que valoriza os direitos fundamentais.

PALAVRAS-CHAVE: Condição jurídica do estrangeiro; lei de migração; direito internacional dos direitos humanos; estatuto do estrangeiro; cidadania.

\section{ABSTRACT}

Objective: To analyze the overcoming of the Foreigner Statute of 1980 and the entry into force of the Migration Law of 2017, as a response to the increase of migratory flows in Brazil, as well as impacts that it may cause in the future.

Methodology: Methodologically, the analysis takes place through the study of the aforementioned law, relating its effectiveness in view of the new migratory challenges and its resulting replacement by a more modern and time-aligned code. As it is a descriptive and exploratory study, the deductive method is used, as well as the bibliographical and historical review of the subject themes.

Results: The Brazilian Migration Law was edited to overcome the differentiation between national and non-national, valuing human dignity and life protection vis-à-vis the place of birth or place of origin. The evolution between the old legislation and the new law is remarkable, considering that the new law confers rights that the Foreigner Statute of 1980 would never grant, affirming Brazil's position in the panorama of 
migrations as a State that is aware of the reality, even without the economic power that the so-called first-world States possess.

Contributions: The main contribution of this study is to demonstrate, by comparing the different laws and reality, the renewed effectiveness of the new law, which deals more adequately with migratory issues through a background that values fundamental rights.

KEYWORDS: Legal condition of foreigners; migration law; international human rights law; foreigner statute; citizenship.

\section{INTRODUÇÃO}

Os episódios armados sempre deixaram marcas nos Estados vizinhos e nos Estados receptores dos deslocados que conseguiram fugir em busca de sobrevivência, colocando a prova até que ponto um Estado que nada tem a ver com o conflito pode barrar a entrada de um solicitante de ajuda. É nesse momento que surge a cooperação internacional e a redução da discricionariedade Estatal frente à proteção da vida.

A política migratória brasileira foi sendo gradativamente alterada após o advento da Constituição Federal de 1988 não restando espaço para uma norma fria que tratava de maneira abstrata e preconceituosamente o estrangeiro, ou seja, como uma potencial ameaça ao Estado. Assim, o Estatuto do Estrangeiro de 1980 ficou ultrapassado frente a uma nova visão nacional e internacional em relação aos novos fluxos migratórios recebidos pelo Brasil.

Somando as demandas da doutrina e os movimentos nacionais de direitos humanos com os impactos da quebra de fronteiras decorrentes da globalização e as experiências suportadas pelo Brasil em 2012, com o aumento de solicitações de entrada de haitianos, e em 2017, com o crescimento significativo de venezuelanos querendo entrar no Brasil pelas fronteiras do norte do país, ficou evidente que o Estatuto do Estrangeiro de 1980 realmente estava obsoleto e precisava ser retirado do ordenamento jurídico. 
Nesse desiderato, em 2017, em consonância com o Direito Internacional dos Direitos Humanos e sob a perspectiva do Estado Constitucional Cooperativo, após anos de debates e espera, entrou em vigor a Lei n. 13.445, conhecida como Lei de Migração, a qual revogou o Estatuto do Estrangeiro de 1980 e inseriu novas regras para política migratória brasileira.

Em razão dessa nova norma e dos impactos que ela pode causar futuramente, a presente pesquisa tem por desígnio descrever e analisar os principais pontos superados do Estatuto do Estrangeiro e as principais diretrizes e garantias da Lei de Migração de 2017.

Por se tratar de um estudo descritivo e exploratório, utiliza-se o método dedutivo, bem como a revisão bibliográfica e histórica dos temas em questão.

\section{ESTATUTO DO ESTRANGEIRO DE 1980 - PROTEÇÃO NACIONAL FRENTE À CONDIÇÃO HUMANA}

O deslocamento de pessoas sempre foi e será uma realidade da espécie humana, não há como mensurar um período inicial ou fatores primordiais para a existência do fluxo migratório. $O$ que se pode afirmar é que existindo violações à vida humana ou às condições prejudiciais de sobrevivência, é natural deixar o local em que se está para assegurar a própria existência.

Validamente, no mundo contemporâneo, tem-se que a conscientização do crescimento do fluxo migratório se deu após a Segunda Guerra Mundial. Isso porque, os constantes ataques a sociedade civil fizeram com que muitas pessoas deixassem suas casas, familiares e países em busca de sobrevivência em outras nações.

Contudo, apesar das políticas migratórias do pós-guerra, como, por exemplo, o Estatuto dos Refugiados de 1951, não se pode olvidar que o mundo ainda detinha sérias preocupações com a possibilidade de novos conflitos. E no Brasil, a apreensão de conflitos internos e externos, nesse período, se tornou maior ainda com a ascensão dos militares ao governo. 
É nesse contexto que, em 1980, sob a égide do regime militar surge o Estatuto do Estrangeiro, o qual visava regulamentar a situação jurídica do não nacional no Brasil em momento de paz, como assevera o artigo 1ㅇ (BRASIL, 1980): "em tempo de paz, qualquer estrangeiro poderá, satisfeitas as condições desta Lei, entrar e permanecer no Brasil e dele sair, resguardados os interesses nacionais".

Resta claro e evidente o interesse do legislador em proteger os brasileiros em detrimento dos estrangeiros, ainda que este não nacional nada tenha a ver com possíveis conflitos que seu país de origem ou outros estejam envolvidos. Outro nítido exemplo apresenta-se no artigo 2ㅇ (BRASIL, 1980):

[...] na aplicação desta Lei atender-se-á precipuamente à segurança nacional, à organização institucional, aos interesses políticos, socioeconômicos e culturais do Brasil, bem assim à defesa do trabalhador nacional. (grifos nossos).

Já nessa leitura preliminar do Estatuto do Estrangeiro, vislumbra-se que a intenção da norma não era dar condições de recepção ao solicitante de entrada no Brasil, mas, sim, assegurar que essa entrada independentemente dos motivos, não afetasse de qualquer maneira o nacional. Nesse ponto, é possível questionar se o estrangeiro estava sendo tratado como ser humano ou como inimigo, pois deveria sempre justificar que merecia estar em solo brasileiro.

Aqui, não se faz um pré-julgamento acerca do poder discricionário de um Estado em permitir ou não a entrada de uma pessoa em seu território. Questiona-se, todavia, se a forma com o que o Brasil, ao regulamentar a condição jurídica do estrangeiro, não criminaliza o não nacional de forma generalizada, como se todos os estrangeiros fossem de certa maneira inimigos e não pessoas (seres humanos).

Novamente, isso fica claro da leitura do artigo 65 (BRASIL, 1980):

[...] é passível de expulsão o estrangeiro que, de qualquer forma, atentar contra a segurança nacional, a ordem política ou social, a tranquilidade ou moralidade pública e a economia popular, ou cujo procedimento o torne nocivo à conveniência e aos interesses nacionais. (grifos nossos) 
Com o advento da atual Constituição Federal, em 1988, o Estatuto do Estrangeiro precisou ser revisto para se adequar as novas premissas constitucionais, que saíram da esfera militar para adentrar ao cenário do Estado Democrático de Direito. Assim, de plano, o aludido estatuto precisou se adaptar ao novo fundamento da República Federativa do Brasil, qual seja, a dignidade da pessoa humana¹.

Outros dispositivos apregoados pela Constituição trouxeram uma nova visão acerca do estrangeiro, demonstrando uma tentativa de mudança de pensamento sobre o não nacional, quais sejam:

Art. 4ำ A República Federativa do Brasil rege-se nas suas relações internacionais pelos seguintes princípios: (...) II - prevalência dos direitos humanos; (...) IX - cooperação entre os povos para o progresso da humanidade; (...). Art. 5ำ Todos são iguais perante a lei, sem distinção de qualquer natureza, garantindo-se aos brasileiros e aos estrangeiros residentes no País a inviolabilidade do direito à vida, à liberdade, à igualdade, à segurança e à propriedade, nos termos seguintes: (...). (BRASIL, 1988).

Ainda nesse cenário, a Declaração de Viena de 1993 trouxe uma importante compreensão acerca dos direitos humanos, valorizando uma tendência de que tais direitos são universais, logo, não devem ser relativizados², mas, sim, tratados de maneira global. Nesse ponto, Silveira e Rocasolano (2010, p.61) esclarecem que:

\footnotetext{
Em relação às particularidades ou relativismos culturais. Em seu artigo 5ํa a declaração, além de reafirmar a universalidade dos direitos humanos, atribuiIhes indivisibilidade, interdependência e inter-relação, mas reconhece a importância do contexto histórico, cultural e religioso, bem como das peculiaridades regionais, numa sentença: "Estado, proteja os direitos humanos independente do seu sistema!". (grifos nossos)
}

\footnotetext{
1 "A dignidade é um valor espiritual e moral inerente à pessoa, que se manifesta singularmente na autodeterminação consciente e responsável da própria vida e que traz consigo a pretensão ao respeito por parte das demais pessoas, constituindo-se um mínimo invulnerável que todo estatuto jurídico deve assegurar, de modo que, somente excepcionalmente, possam ser feitas limitações ao exercício dos direitos fundamentais, mas sempre sem menosprezar a necessária estima que merecem todas as pessoas enquanto seres humanos45 e a busca ao Direito à Felicidade". (MORAES, 2017.p.18)

${ }^{2}$ Explica Flávia Piovesan que para os relativistas as diferenças de cada região do globo caracterizam um pluralismo cultural, dessa maneira, não seria possível uma formação moral universal. Em contrapartida, o universalismo visa o coletivo, compreendendo que o indivíduo é parte integrante da sociedade, assim, o fundamento dos direitos humanos é a dignidade da pessoa humana, sendo um valor intrínseco à própria condição humana. (PIOVESAN, 2017).
} 
Em face do acima exposto, nota-se que apesar de o Estatuto do Estrangeiro de 1980 ter sido elaborado à luz do autoritarismo e dos constantes receios de conflitos armados, as tendências globais de proteção aos direitos humanos influenciaram a maneira de visualizar o estrangeiro, não só em solo brasileiro, mas em qualquer lugar do mundo, uma vez que a proteção deixou de ser pautada nas condições de nacionalidade e passaram ser vislumbradas no princípio da dignidade da pessoa humana como valor universal.

\section{OS FLUXOS MIGRATÓRIOS}

A migração é um assunto contemporâneo e de importante debate. Não há como negar a existência e a necessidade de oferecer apoio a pessoas em situação risco. É fato que as crises humanitárias e o contexto político existente em vários Estados influenciaram e influenciam diretamente esse deslocamento (interno e externo) e, ainda, impedem, por muitas vezes, o retorno dos nacionais aos seus locais de origem (ONU, 2009).

Os instrumentos normativos internacionais definem quem são os refugiados, todavia, abrangem, em regra, situações que envolvem conflitos bélicos, o que torna as normas insuficientes frente aos atuais fluxos migratórios, os quais ultrapassam a conceituação estratificada, uma vez que existem outros tipos de deslocamentos que não se enquadram na categoria de refugiados. Em outras palavras, ultrapassam a barreira de escolha de quem merece ou não acolhimento.

Nesse ponto, para fins de melhor compreensão, convém analisar quem são os migrantes, os refugiados, os visitantes e os residentes fronteiriços. Os primeiros, objeto de estudo da presente pesquisa, são aqueles que saem de um país ou região para outros, trata-se de uma visão geográfica, sendo um gênero dos termos imigrante e emigrante.

Os refugiados, consoante o Estatuto dos Refugiados de 1951 (ONU, 1951) são aqueles: 
(...) Que, em consequência dos acontecimentos ocorridos antes de $1^{\circ}$ de janeiro de 1951 e temendo ser perseguida por motivos de raça, religião, nacionalidade, grupo social ou opiniões políticas, se encontra fora do país de sua nacionalidade e que não pode ou, em virtude desse temor, não quer valer-se da proteção desse país, ou que, se não tem nacionalidade e se encontra fora do país no qual tinha sua residência habitual em consequência de tais acontecimentos, não pode ou, devido ao referido temor, não quer voltar a ele. No caso de uma pessoa que tem mais de uma nacionalidade, a expressão "do país de sua nacionalidade" se refere a cada um dos países dos quais ela é nacional. Uma pessoa que, sem razão válida fundada sobre um temor justificado, não se houver valido da proteção de um dos países de que é nacional, não será considerada privada da proteção do país de sua nacionalidade.

Ainda no tocante aos refugiados é importante mencionar que o Protocolo Adicional de 1967 retirou a limitação geográfica de aplicação do Estatuto, que antes era válido somente para o continente europeu, e ainda, ampliou o marco temporal para qualquer evento, não se limitando aos acontecimentos referentes à Segunda Guerra Mundial (ONU, 1967).

Os visitantes são as pessoas que adentram outros Estados para fins de turismo, comércio, estudo ou quaisquer outros motivos que não estejam relacionados com a intenção de se estabelecer definitivamente ou sem período marcado.

Já os residentes fronteiriços são aqueles que residem em locais de fronteira, cujo o acesso ao outro Estado não depende necessariamente de verificação documental ou quaisquer outros tipos de comprovação, um clássico exemplo disso, é a fronteira da cidade de Ponta Porã, cidade de Mato Grosso do Sul, no Brasil, com a cidade de Pedro Juan Caballero, no Paraguai. Ali existe um livre trânsito entre os residentes dos dois países, mas com a manutenção de residência em cada uma das cidades.

Superado as diferenças conceituais, volta-se para a questão da migração, a qual não possuía uma regulamentação fixa, tal como os refugiados, que possuem instrumentos normativos internacionais de proteção. Registra-se, que não é objeto de análise verificar se os aludidos instrumentos são bons ou ruins, o fato é que tais documentos existem diferentemente do que ocorre com os migrantes.

É cediço que não há somente situações de deslocamento por causas de perseguições relativos à raça, à religião, à nacionalidade, aos fatores políticos ou a 
grupos sociais, conceitos outrora estratificados e imutáveis que conferem proteção aos refugiados. Existem situações que envolvem deslocamento por questões climáticas, econômicas, emprego, fome, doenças e outros.

Não muito longe desse cenário, o Brasil foi surpreendido no ano de $2012 \mathrm{com}$ um número expressivo de haitianos solicitando entrada, em razão dos desastres ambientais suportados pelo país, tanto é que o Conselho Nacional de Imigração brasileiro emitiu a Resolução Normativa no 97, de 12 de janeiro de 2012, a qual conferia condições jurídicas diferentes, facilitadoras, de entrada para esse grupo específico de pessoas.

Para que se possa compreender melhor a situação apresentada, "no ano de 2011 foram concedidos 709 vistos de permanência/residência, no ano de 2012 foram concedidos 4.682 vistos de permanência/residência" (FÉLIX, SANTOS, 2015, p.2098).

Guiado pelo mesmo espírito, o Brasil abriu as fronteiras para o recebimento de venezuelanos, ante a crise econômica suportada pelo país vizinho:

\begin{abstract}
Desde 2015, após o presidente Nicolás Maduro perder as eleições parlamentares da Venezuela, parte da população venezuelana começou a emigrar em maiores números para alguns países da América Latina, principalmente Colômbia e Brasil. Pressões internacionais diversas acrescentadas às crises internas do modelo político que vigorou neste país desde o final da década de 1990 culminaram em crises econômicas, sociais e de abastecimento de alimentos. Diante do aumento dos fluxos de venezuelanos atravessando a fronteira e solicitando refúgio no Brasil, em fevereiro de 2017 o Conselho Nacional de Imigração editou a Resolução Normativa $n^{\circ}$ 126, que favoreceu a regularização da imigração venezuelana no país. (FGV, 2018, p.3)
\end{abstract}

Num primeiro momento, essa visão humanitária demonstrada pelo Brasil pode ter acontecido por razões fronteiriças ou na tentativa de estabelecer fama de país acolhedor, mas ao se analisar profundamente, nota-se que o Brasil, com as Resoluções n. 97 de 2012 e n. 126 de 2017, na verdade, acabou positivando no cenário doméstico direitos humanos para os migrantes.

Como aponta Norberto Bobbio (1992, p.30): 
Os direitos humanos nascem como direitos naturais universais, desenvolvem-se como direitos positivos particulares (quando cada Constituição incorpora Declarações de Direitos) para finalmente encontrar a plena realização como direitos positivos universais.

Em ambos os casos, se não houvesse uma chancela estatal de acolhimento, diversas vidas estariam em risco, pois os solicitantes de entrada por motivos climáticos e econômicos, não se enquadram no rol de proteção assegurado pelo Estatuto dos Refugiados de 1951 e seu respectivo protocolo adicional.

O Brasil teve que se adequar, então, para afirmar e realizar o novo paradigma dos direitos humanos aos recentes fluxos migratórios influenciados diretamente pela globalização. Para Jesús Lima Torrado (2000, p.44):

[...] la globalización, por la profundidad, intensidad y extensión con que penetra el tejido social de todos los países del mundo, afecta a todas las cuestiones que son objeto de estúdio en la Teoría de los Derechos Humanos. La globalización afecta decisivamente a un presupuesto teórico de los derechos tan importante como es la teoría del poder. Afecta además a todos y cada uno de sus elementos estructurales: al sujeto, al objeto . . . siendo especialmente importante sin embargo, su repercusión sobre el sistema de garantías. $^{3}$

O avanço da mobilidade humana incentivado por motivos econômicos, legais, sociais e, sobretudo, pelos avanços tecnológicos em diversos setores, fizeram com que os migrantes mantivessem contatos com familiares e pessoas de outras localidades (AGUILERA URQUIZA; RIBEIRO, 2017, p. 249) que talvez, em outros tempos, não teriam. Assim, as fronteiras foram diminuindo gradativamente.

Aguilera Urquiza e Ribeiro (2017, p.249) nessa linha ponderam que:

Com a maior mobilidade humana e o consequente maior contato entre os povos, diversas questões delicadas podem ser postas em observação. Uma delas é o aumento do contato entre culturas verificado pelo maior fluxo de mobilidade humana que a globalização acarretou.

\footnotetext{
${ }^{3}$ Tradução livre do Espanhol para o Português: a globalização, por causa da profundidade, intensidade e extensão com que o tecido social de todos os países do mundo, afeta todas as questões que são objeto de estudo na Teoria dos Direitos Humanos. A globalização afeta decisivamente a um pressuposto teórico dos direitos tão importante como é a teoria do poder. Ademais, afeta todos e cada um de seus elementos estruturais: o sujeito, o objeto... sendo especialmente importante, no entanto, o seu impacto no sistema de garantias.
} 
Assim resta evidente que não só as questões de ajuda humanitária fizeram com que o Brasil acolhesse os haitianos e venezuelanos em situações precárias. Nota-se, que a globalização tem parte nisso, afinal, indo além das fronteiras, o contato entre possíveis familiares, conhecidos e o mundo assistindo ao vivo as medidas que seriam tomadas pelo Brasil afetaram o poder de decisão do Estado em ajudar ou não.

Em que pese à dinâmica brasileira em criar resoluções para solucionar problemas específicos, muitas ocorrências ainda poderiam ser solucionadas, formalmente, pelo Estatuto do Estrangeiro de 1980, anteriormente analisado, o qual, todavia, não confere garantias efetivas aos migrantes.

Nessa conjuntura e seguindo perspectiva do Direito Internacional dos Direitos Humanos restou aprovada no ordenamento jurídico brasileiro a Lei n. 13.445 de 2017, denominada de Lei de Migração, que abarca não somente o estrangeiro comum que pretende entrar e sair do Brasil, mas também os migrantes que não possuem intenção de saída, em razão de situações que não se enquadram na categoria dos refugiados, todavia, se enquadram na proteção dos direitos humanos.

\section{LEI DE MIGRAÇÃO DE 2017}

Com a consolidação da Constituição Federal de 1988 e o crescimento do ideal republicano, valorizando o Estado Democrático de Direito, o pensamento acerca do estrangeiro como ameaça ao Estado começou a ser alterado gradativamente.

Em 2013, após outras tentativas o então senador Aloysio Nunes Ferreira apresentou ao Senado o Projeto de Lei n.288/2013, o qual tinha por escopo instituir uma norma que substituísse o Estatuto do Estrangeiro e regulamentasse, de fato, direitos e deveres dos não nacionais que desejassem entrar no Brasil para se estabelecer ou não, visando ainda retirar o estereótipo de que o estrangeiro era uma ameaça à segurança nacional e diminuir a xenofobia.

Após anos de debates, com críticas positivas e negativas por parte dos defensores dos direitos humanos dos migrantes, e críticas positivas e negativas por 
parte dos integrantes do Congresso Nacional, de toda sociedade e governo, em 2017, o projeto foi aprovado pelas casas legislativas e seguiu para sanção presidencial, a qual ocorreu em 24 de maio de 2017.

Em análise preliminar da denominada Lei de Migração, n. 13.445 de 2017, observa-se que a lei define quem são os imigrantes, os emigrantes, os residentes fronteiriços, os visitantes e os apátridas, e ainda, dispõe expressamente que a Lei de Migração não afeta os documentos internacionais assinados pelo Brasil acerca dos refugiados, asilados e pessoas ligadas à diplomacia, tampouco as normas domésticas.

A lei ao definir quem são os sujeitos de direitos da norma, de certa forma, deixa expresso que todas as modalidades de estrangeiros podem se valer do novo instrumento legal. Assim, não há necessidade de a doutrina, leia-se estudiosos da área, discutir quem são ou não os beneficiados, sendo então meio caminho andado quando se trata de pessoas que estão em situação de risco e precisam de uma resposta célere do governo.

Diferentemente do que ocorria com o Estatuto do Estrangeiro de 1980, a Lei de Migração antes de demonstrar quais os direitos conferidos pelo Brasil aos não nacionais assevera de plano os princípios e as diretrizes a serem seguidas quando se trata da política migratória, sendo este rol composto de vinte e dois incisos.

Dentre os principais princípios e diretrizes, convém destacar alguns pontos:

\begin{abstract}
Art. 3․ I - universalidade, indivisibilidade e interdependência dos direitos humanos; II - repúdio e prevenção à xenofobia, ao racismo e a quaisquer formas de discriminação; III - não criminalização da migração; (...)VI acolhida humanitária; (...) XI - acesso igualitário e livre do migrante a serviços, programas e benefícios sociais, bens públicos, educação, assistência jurídica integral pública, trabalho, moradia, serviço bancário e seguridade social; (...). (BRASIL, 2017).
\end{abstract}

Ao consignar que os direitos humanos são universais, indivisíveis e interdependentes, a legislação aponta sua preocupação com a forma que tais direitos são disciplinados no cenário doméstico, esse dispositivo confirma o posicionamento do Brasil frente ao proposto pelo Direito Internacional dos Direitos Humanos, 
ratificando que os referidos direitos devem ser protegidos independentemente da situação a ser enfrentada.

O inciso II nem deveria existir. Todavia, em razão do contexto histórico, social e político que envolveu a elaboração do Estatuto do Estrangeiro de 1980, que acabou acarretando uma visão, muitas vezes, errônea do não nacional, tornou-se deveras necessário colocar que o Brasil repudia veementemente quaisquer práticas de xenofobia, racismo e outras maneiras de discriminação ao estrangeiro em solo nacional.

O inciso III apregoa que um dos princípios basilares da Lei de Migração é a não criminalização do migrante. Novamente, quando se trata de direitos humanos, tal dispositivo nem deveria fazer parte da legislação. Pelo contrário, deveria ser uma premissa absoluta e cumprida por todos. Contudo, mais uma vez, ante os fatores que influenciaram o Estatuto do Estrangeiro de 1980. E os recentes acontecimentos nos Estados Unidos e na Europa, a norma acertou em expor que o Brasil não concorda com o pré-julgamento, criminalização, feito ao migrante.

Para Amaral e Costa (2017, p.225):

\begin{abstract}
A Lei no 13.445/2017, ao facilitar a inclusão dos imigrantes na sociedade brasileira e tratar a migração como tema de direitos humanos e não mais apenas de segurança nacional, leva o Brasil à contramão da tendência moderna, observada principalmente nos Estados Unidos e na Europa, de criminalizar as migrações ao adotar a não criminalização da política migratória como princípio.
\end{abstract}

É válido destacar a importância do inciso VI, que dispõe sobre o instituto da acolhida humanitária. Esse novo instituto veio para assegurar que qualquer pessoa, apátrida ou nacional de um Estado, por motivos de instabilidade institucional ou conflito armado, calamidades ambientais, transgressão de direitos humanos ou de Direito Internacional Humanitário, poderá requerer entrada no Brasil (BRASIL, 2017, art.14, §3ํ). A partir da vigência da norma, entende-se que o Brasil reconhece expressamente novas modalidades de refúgio, um passo à frente da comunidade internacional, afinal, reconhece-se que não existem somente as pessoas enquadradas no Estatuto dos Refugiados. 
Interessante analisar também o inciso $\mathrm{XI}$, o qual permite ao migrante acesso igualitário e livre aos serviços básicos de saúde, educação, trabalho e afins. Referido dispositivo se coaduna com o exposto na Constituição Federal de 1988 em seu artigo $5^{\circ}$, o qual apregoa que não haverá tratamento diferenciado entre brasileiros e estrangeiros.

No que se refere às garantias aos migrantes, destaca-se para considerações três dispositivos, quais sejam:

Art. 4ㅇ․ Ao migrante é garantida no território nacional, em condição de igualdade com os nacionais, a inviolabilidade do direito à vida, à liberdade, à igualdade, à segurança e à propriedade, bem como são assegurados: (...) III - direito à reunião familiar do migrante com seu cônjuge ou companheiro e seus filhos, familiares e dependentes; (...) VI - direito de reunião para fins pacíficos; (...) XII - isenção das taxas de que trata esta Lei, mediante declaração de hipossuficiência econômica, na forma de regulamento; (...).(BRASIL, 2017).

O inciso III preconiza a reunião familiar do migrante e seus familiares. Esse dispositivo traz consigo uma carga emocional imensurável. Isso porque, quando falamos de pessoas solicitando entrada porque não podem voltar aos seus Estados de origem o mínimo que se espera é a manutenção da unidade familiar. Começar a vida em um novo Estado e separado de seus entes queridos é contraditório com o princípio da dignidade humana, corolário do Direito Internacional dos Direitos Humanos. Assim, essa positivação evita com que famílias sejam desfeitas e o novo começo se torne mais difícil e desumano.

Indo totalmente em sentido contrário ao Estatuto do Estrangeiro de 1980, a Lei de Migração reconhece que o migrante pode se reunir para fins pacíficos, como assegura o inciso $\mathrm{VI}$, do artigo $4^{\circ}$. Em uma análise rápida esse dispositivo pode passar despercebido, no entanto, esse inciso é importante, pois garante que o migrante se reúna com pessoas na mesma situação ou não para buscar melhorias, apoio ou qualquer outra medida lícita. Tal permissão se coaduna com a política e ideia de que o migrante não é uma ameaça ao Estado.

O inciso XII preconiza que o migrante hipossuficiente não arcará com as custas procedimentais. Em outras palavras, o migrante poderá solicitar documentos, 
certidões referentes à sua condição no Brasil, documentos correlatos e outros sem ônus. Na mesma toada dos demais dispositivos, esse inciso é relevante, porque ao chegar aos aeroportos, portos ou fronteiras, muitos migrantes não possuem condições financeiras nem para o custo de alimentação quanto mais para a burocracia brasileira. Ratificar a isenção é uma nítida demonstração do acolhimento nacional e facilitação de sua permanência.

Existem outros diversos dispositivos assecuratórios de direitos aos migrantes, cuja análise se alongaria demasiadamente e não atingiria o foco do presente estudo. O objetivo da pesquisa é analisar a mudança de visão do estrangeiro ameaça para o migrante respeitado, justificado não só pela globalização, mas também pelo avanço do conceito do Estado Constitucional Cooperativo, uma vez que a ideia de Estado soberano e absoluto proposto por Jean Bodin restou superado exigindo-se dos Estados uma maior integração e solidariedade.

Nesse sentido, lecionam Silveira e Fernandes (2016, p.10):

(...) o Estado Constitucional Cooperativo busca agregar ao Estado Constitucional de Direito elementos outros que não uma unidade pautada na soberania absoluta, mas suavizando-a de modo que seja balanceada com os novos anseios de cooperação, solidariedade e integração entre Estados e, também, entre eles e organizações internacionais.

Ainda nesse contexto, levando-se em consideração a ideia de Silveira e Rocasolano (2010) haveria por parte do Brasil uma conscientização da solidariedade como valor universal no processo de dinamogenesis, quando o Estado buscou positivar novos fluxos migratórios, até então abstratos (sem proteção jurídica).

Assim sendo, esses novos direitos humanos surgem a partir de um processo dinamogênico, em que são admitidos e, posteriormente, positivados os valores que respaldam tais direitos, sendo sintetizados na consolidação da dignidade humana. Isto é, o ordenamento jurídico normatiza um valor abstrato, para que este tenha proteção do Estado.

A positivação de uma lei que visualiza o migrante como sujeito de direitos e não como ameaça, e ao mesmo tempo oferece proteção, a priori, - pois só o decurso 
do tempo responderá - poderá quebrar um paradigma ventilado por Boaventura de Souza Santos, ao menos no Brasil, de que os direitos humanos são incontestáveis, mas "a grande maioria da população mundial não é sujeito de direitos humanos, é objeto de discursos de direitos humanos". (SANTOS, 2014, p.12)

A Lei de Migração como visto ultrapassa a estratificação do conceito de refugiado reconhecendo de fato que outras situações também merecem abrigo. Ademais, confere direitos aos não nacionais até então inexistentes no ordenamento jurídico brasileiro.

\section{CONCLUSÃO}

A busca por melhores condições de vida faz parte do cotidiano da espécie humana, principalmente quando se trata de questões relativas à sobrevivência. $O$ medo, a insegurança, a fome e diversos outros fatores, levam as pessoas a se arriscarem em outros países e em outras culturas sem saber se serão ou não bem recebidos.

O cenário deixado pela Segunda Guerra Mundial acendeu o debate sobre o que fazer com os refugiados, milhares de pessoas ficaram sem suas casas e famílias, assim como, sem uma nação para voltar e recomeçar. Nesse contexto, a Organização das Nações Unidas se prontificou em criar um órgão responsável por dar condições a essas pessoas, criando o Alto Comissariado das Nações Unidas para os Refugiados, que em seguida aprovou em conjunto com os países vencedores o Estatuto dos Refugiados de 1951.

Ocorre que o referido estatuto possui um conceito engessado de quem são os refugiados. Em outras palavras, possui um conceito congelado de quem precisa ou não de acolhimento, como se certas palavras fossem capazes de qualificar alguém para receber ajuda de outro Estado.

A quebra de fronteiras físicas, culturais, econômicas e tecnológicas influenciadas pela globalização fez com que as pessoas se tornassem cidadãs do 
mundo, principalmente quando se trata de indivíduos que deixam suas origens ou local habitual a procura de melhores condições de vida, ou ainda, em busca de simplesmente se manterem vivas.

Em que pese essa nova característica do ser humano, a depender dos motivos que levam as pessoas a saírem de suas nações, provavelmente não serão bem recebidas em outras, por ausência de instrumentos legais ou por medo de novas pessoas chegando para permanecer.

No Brasil, o Estatuto do Estrangeiro de 1980 retratava a visão fechada da política migratória adotada pelo país. Isso porque, o arcabouço econômico, social e político que envolveu a elaboração do aludido estatuto foi diretamente influenciado por medo de novos conflitos armados no mundo, assim o estrangeiro era visto como uma ameaça ao Estado.

Felizmente, houve um avanço no pensamento constitucional brasileiro com o esgotamento do governo militar e ascensão dos valores democráticos. A Constituição Federal de 1988 pautada no princípio da dignidade humana buscou equiparar o nacional e o não nacional, na medida do possível. Certamente, foi um importante avanço social e político.

Nesse contexto, o Brasil, considerado um dos melhores países em infraestrutura e oportunidades da América do Sul, começou a receber gradativamente vários migrantes por motivos alheios aos aceitos pelo Estatuto dos Refugiados, sendo cogente a elaboração de resoluções para auxiliar e alguns casos até mesmo conter a entrada de migrantes, em razão da ausência de um instrumento legal capaz de atender as novas necessidades.

Com efeito, modernizando sua política migratória, sob as novas perspectivas do Direito Internacional dos Direitos Humanos, acerca do crescente número de refugiados e deslocados no mundo e, principalmente no Brasil, o direito brasileiro introduziu no ordenamento jurídico doméstico a Lei de Migração de 2017, a qual trouxe a desmistificação do estrangeiro como ameaça e tem por pano de fundo a dignidade humana. 
A nova lei assegura a todos os estrangeiros, agora denominados migrantes, o direito de entrar no Brasil, seja por motivo de atração turística, seja por necessitar de ajuda e não se enquadrar na categoria de refugiados proposta por um estatuto criado no cenário pós-guerra.

Esse instrumento normativo ainda confere direitos que o Estatuto do Estrangeiro de 1980 jamais concederia, afirmando a posição do Brasil no panorama das migrações como uma nação que está atenta a realidade, mesmo sem ter o poder econômico que os países ditos de primeiro mundo possuem.

Por fim, apesar de a lei ser recente e pouco conhecida, espera-se que os dispositivos acolhedores atinjam de maneira eficaz os atuais e novos fluxos migratórios recebidos pelo Brasil. E ainda sirvam de exemplo para outros Estados.

\section{REFERÊNCIAS}

AGUILERA URQUIZA, Antonio Hilário; RIBEIRO, Leonardo Cavallini. Paradoxos da Globalização, Fronteiras Culturais e Direitos Humanos. Revista Direito UFMS, Campo Grande, MS. v.3. n.2. p. 241-260. jul./dez. 2017.

AMARAL, Ana Paula Martins; COSTA, Luiz Rosado. A (não) criminalização das migrações e políticas migratórias no Brasil: do Estatuto do Estrangeiro à nova Lei de Migração. Revista Justiça do Direito, v. v. 31, 2017.

BOBBIO, Norberto. A era dos direitos. Trad. Carlos Nelson Coutinho. Rio de Janeiro: Campus, 1992.

BRASIL. Lei n. 13.445 de 24 de maio de 2017. Lei de Migração. Disponível em: http://www.planalto.gov.br/ccivil_03/_ato2015-2018/2017/lei/L13445.htm. Acessado em: 17.06.2018.

. Lei n. 6.015 de 19 de agosto de 1980. Estatuto do Estrangeiro. Disponível em: http://www.planalto.gov.br/ccivil_03/leis//6815.htm. Acessado em: 17.06.2018.

Constituição Federal de 1988. Promulgada em 5 de outubro de 1988. Disponível em http://www.planalto.gov.br/ccivil_03/constituicao/constituição.htm. Acessado em: 25.05.2018.

FELIX, Ynes da Silva; SANTOS, Ana Carolina dos. Análise do Fluxo Migratório Haitiano a partir da Resolução Normativa № 97 de 12 janeiro de 2012. In: XII Congresso Internacional dos Direitos Humanos - CIDH, 2015, Campo Grande - 
MS. Anais do XII Congresso Internacional dos Direitos Humanos - Fronteiras dos Direitos Humanos - Direitos Humanos nas Fronteiras. Campo Grande: Congresso Internacional de Direitos Humanos, 2015. v. 12. p. 2094-2105. Disponível em: https://cidh.ufms.br/mais-sobre-nos/anais/. Acessado em: 10.07.2019.

FGV, DAPP. Desafio Migratório em Roraima Repensando a política e gestão da migração no Brasil. In Policy Paper - Imigração e Desenvolvimento. Rio de Janeiro, 2018. Disponível em: http://dapp.fgv.br/wp-content/uploads/2018/03/Desafiomigrato\%CC\%81rio-Roraima-policy-paper.pdf. Acessado em: 17.06.2018

MORAES, Alexandre de. Direito constitucional. 33. ed. rev. e atual. São Paulo: Atlas, 2017.

ONU, ACNUR. Convenção Relativa ao Estatuto Dos Refugiados (1951). 1951. Disponível em: http://www.acnur.org/fileadmin/Documentos/portugues/BDL/Convencao_relativa_ao_ Estatuto_dos_Refugiados.pdf. Acessado em: 17.05.2018.

Protocolo de 1967 Relativo ao Estatuto dos Refugiados. Disponível em:http://www.acnur.org/fileadmin/Documentos/portugues/BD_Legal/Instrumentos_I nternacionais/Protocolode_1967.pdf?file=fileadmin/Documentos/portugues/BD_Legal /Instrumentos_Internacionais/Protocolo_de_1967. Acessado em: 17.05.2018.

- Tendências Globais 2009: Refugiados, Solicitantes de Refúgio, Repatriados, Pessoas Deslocadas. Disponível em: http://www.acnur.org/fileadmin/Documentos/portugues/Publicacoes/2010/Tendencias _Globais_2009.pdf. Acessado em: 26.06.2018.

PIOVESAN, Flávia. Direitos humanos e o direito constitucional internacional. 17. ed., rev. e atual. - São Paulo: Saraiva, 2017.

SANTOS, Boaventura de Sousa. Se Deus fosse um ativista dos direitos humanos. 1. ed. São Paulo: Cortez, 2014.

SILVEIRA, Vladmir Oliveira da; e ROCASOLANO, Maria Mendez. Os direitos humanos: conceitos, significados e funções. São Paulo: Saraiva, 2010.

SILVEIRA, Vladmir. Oliveira da; FERNANDES, Ana Carolina Souza. A Crise Migratória na União Europeia e a Proteção dos Direitos Humanos sob a Perspectiva do Estado Constitucional Cooperativo. In: Graziela lensue; Luciani Coimbra de Carvalho. (Org.). Migração, Direitos Humanos e Cooperação Jurídica Internacional. 1ed., 2016, v. 1.

TORRADO, Jésus Lima. Globalización y Derechos Humanos. Universidad de La Rioja, Anuario de filosofía del derecho, oำ17, 2000, págs. 43-74. 